\title{
No association between previous autoantibody expression and development of SARS-CoV-2.
}

Frank Sullivan ( $\square$ fms20@st-andrews.ac.uk)

University of St Andrews https://orcid.org/0000-0002-6623-4964

Agnes Tello

Edinburgh Clinical Trials Unit, Usher Institute, University of Edinburgh

Petra Rachhaus

Tayside Clinical Trials Unit

\section{Fergus Daly}

University of St Andrews

\section{Research Article}

Keywords: COVID-19, Serum biomarkers, EarlyCDT-Lung, Lung Cancer, Mortality prediction, current or exsmokers

Posted Date: August 26th, 2021

DOI: https://doi.org/10.21203/rs.3.rs-842075/v1

License: (c) (1) This work is licensed under a Creative Commons Attribution 4.0 International License. Read Full License 


\section{Abstract}

Background: Patients who exhibit the more severe forms of SARS-CoV-2 exhibit activation of immunological and inflammatory cascades. Participants (current or ex-smokers with at least 20 years pack history) in a trial (ECLS) of autoantibody detection to predict lung cancer risk had seven autoantibodies measured five years before the pandemic. This study compared the response to Covid infection in study participants who tested positive and negative to antibodies to tumour associated antigens: p53, NY-ESO-1, CAGE, GBU4-5, HuD, MAGE A4 and SOX2.

Methods: Autoantibody data from the Early Diagnosis of Lung Cancer, Scotland (ECLS) study was deterministically linked to the EAVE II database which is a national, real-time prospective cohort using Scotland's health data infrastructure, to describe the epidemiology of SARS-CoV-2 infection, patterns of healthcare use and outcomes. The strength of associations was explored using a network algorithm for exact contingency table significance testing by permutation.

Results: There were no significant differences discerned between SARS-CoV-2 test results and EarlyCDTLung test results (positive / negative) $(p=0.734)$. An additional analysis of ICU admissions detected no significant differences between those who tested positive and negative. Subgroup analyses showed no difference in COVID -19 positivity or death rates amongst those diagnosed with COPD with positive and negative EarlyCDT results.

Conclusions: This hypothesis generating study demonstrated no clinically valuable or statistically significant associations between EarlyCDT positivity in 2013-15 and the likelihood of SARS-CoV-2 positivity in 2020, ICU admission or death in all participants (current or ex-smokers with at least 20 years pack history) or in those with COPD or lung cancer

\section{Introduction}

Overactivation of the immune system in patients with severe SARS-CoV-2 is known to cause harmful tissue damage and is associated with poor clinical outcomes. Conversely it is known that people with immune deficiency have an increase in mortality when admitted to hospital with Covid-19. It is not yet clear whether patients who exhibit such robust immune response to SARS-CoV-2 have higher background levels of antibody and autoantibody(AAB) responsiveness when compared to patients who develop mild disease. One form of antibody response to the development of abnormal cell surface characteristics are tumour associated autoantibodies. These proteins are produced early in tumorigenesis, being measurable up to 5 years before the development of clinical symptoms. They represent biologically amplified markers, increasing the detectable signal for the corresponding level of antigen. They persist in the circulation with half-lives of typically up to 30 days.

The EarlyCDT-Lung test is an enzyme-linked immunosorbent assay (ELISA) that measures seven autoantibodies, each with individual specificity for the following tumour associated antigens (TAA): p53, NY-ESO-1, CAGE, GBU4-5, HuD, MAGE A4 and SOX2. A sample is positive if at least one AAB is elevated 
above a predetermined cut-off. The test has been developed throughout the pre-clinical, clinical assay validation and retrospective biomarker development pathway stages. In cohort studies it has demonstrated a specificity of $91 \%$ and sensitivity of $41 \%$. ECLS was a phase IV biomarker trial of Early CDT in 12208 smokers and ex-smokers age 50-75 at risk of developing lung cancer using Early CDT followed by imaging recruited from General Practices in Scotland. 6088 study subjects in the intervention arm received the EarlyCDT-Lung test at the baseline visit and 598 (9.8\%) had a positive autoantibody result. In the two year analysis of the Early Diagnosis of Lung Cancer Scotland (ECLS) trial the EarlyCDTLung was shown to reduce late stage presentations of lung cancer.

We have investigated whether the production of autoantibodies in response to cell surface abnormalities in cancer, as measured by the baseline EarlyCDT-Lung test in the ECLS trial, was associated with more severe disease in at risk participants (current and former smokers) who then develop a SARS-CoV-2 infection 5-6 years later.

\section{Methods}

Participants aged 50-75 who were current or ex-smokers with at least 20 pack years history were recruited to ECLS between December 2013 and April 2015 and all baseline assessments of plasma antibody levels occurred during this time. SARS-CoV-2 status and outcome data for ECLS participants during 2020 were obtained from the EAVE II database which is a national, real-time prospective cohort using Scotland's health data infrastructure, to describe the epidemiology of SARS-CoV-2 infection, patterns of healthcare use and outcomes. , Data from both sources data was linked using Scotland's Community Health Index Number the University of Dundee's Health Informatics centre (HIC) Safe Haven.

The strength of associations was explored using a network algorithm for exact contingency table significance testing by permutation. This approach is appropriate for the sparseness of the data here, where an approximate chi-squared analysis would provide severely discrepant outputs. (For $2 \times 2$ contingency tables the network algorithm reduces identically to Fisher's exact test.)

\section{Results}

Table 1 shows no difference in SARS-CoV-2 positivity or death rates amongst those with positive and negative EarlyCDT lung test results in all study subjects.

Nil significance found.

\section{Discussion}

No clinically valuable or statistically significant associations between EarlyCDT lung positivity in 2013-15 and the likelihood of SARS-CoV-2 positivity in 2020, ICU admission or death were found. This was true for the entire study cohort and in subgroup analyses of at risk participants (current and former smokers) with Lung Cancer and COPD. Strengths of the study include the community based sampling of the ECLS 
cohort, large numbers of the cohort who laboratory validated had a Covid-19 test validated laboratory and outcome assessment. Weaknesses include the time which had elapsed between the initial trial and the onset of the pandemic as well as small numbers of study subjects who were in the subgroup analyses.

Evidence is emerging that some routine clinical laboratory tests, such as lymphocyte count, lactate dehydrogenase, and D-dimer, are known to be affected in patients with COVID-19. Other studies have shown significant differences in inflammatory markers among patients who have required ICU admission compared to patients who did not and markers of infection such as C-reactive protein, procalcitonin, and ferritin are, as expected, correlated with severe disease.

This hypothesis generating study has failed to find a clear association between the expression of tumour associated antibodies in the ECLS cohort at risk participants (all current and former smokers) and the development of SARS-CoV-2 and its complications five years later.

\section{Declarations}

Conflicts of Interest

FS, AT, PR and FD have all worked on research grants funded by the Lung Foundation related to this study,

ClinicalTrials.Gov registration number NCT01925625

\section{References}

[1] Zhang, B. et al.

Immune phenotyping based on neutrophil-to-lymphocyte ratio and IgG predicts disease severity and outcome for patients with COVID-19. medRxiv 2020.03.12.20035048 (2020).

doi:10.1101/2020.03.12.2003504

[2] Geretti AM, Stockdale AJ, Kelly SH, Cevik M, Collins S, Waters L, Villa G, Docherty A, Harrison EM, Turtle L, Openshaw PJM, Baillie JK, Sabin CA, Semple MG. Outcomes of COVID-19 related hospitalization among people with HIV in the ISARIC WHO Clinical Characterization Protocol (UK): a prospective observational study. Clin Infect Dis. 2020 Oct 23:ciaa1605. doi: 10.1093/cid/ciaa1605.

[3] Widjaja G, Turki Jalil A, Sulaiman Rahman H, Kamal Abdelbasset W, Bokov DO, Suksatan W, Ghaebi M, Marofi F, Gholizadeh Navashenaq J, Jadidi-Niaragh F, Ahmadi M. Humoral immune mechanisms involved in protective and pathological immunity during COVID-19. Hum Immunol. 2021 Jul 1:S01988859(21)00174-9. doi: 10.1016/j.humimm.2021.06.011.

[4] Zhong, L., Coe, S.P., Stromberg, A.J., Khattar, N.H., Jett, J.R. and Hirschowitz, E.A. (2006) Profiling Tumor-Associated Antibodies for Early Detection of Non-Small Cell Lung Cancer. Journal of Thoracic Oncology, 1, 513-519. https://doi.org/10.1016/S1556-0864(15)30352-X 
[5] Chu GWC, Lazare K, Sullivan FM. Serum and blood based biomarkers for lung cancer screening: a systematic review. BMC Cancer 2018) 18:181 DOI 10.1186/s12885-018-4024-3

[6] Anderson, K.S. and LaBaer, J. (2005) The Sentinel Within: Exploiting the Immune System for Cancer Biomarkers. Journal of Proteome Research, 4, 1123-1133. https://doi.org/10.1021/pr0500814

[7] Lam S, Boyle P, Healey GF, Maddison P, Peek L, Murray A, Chapman CJ, Allen J, Wood WC, Sewell HF, Robertson JF. EarlyCDT-Lung: an immunobiomarker test as an aid to early detection of lung cancer. Cancer Prev Res (Phila). 2011 Jul;4(7):1126-34. doi: 10.1158/1940-6207.CAPR-10-0328.

[8] Murray A, Chapman CJ, Healey G, Peek LJ, Parsons G, Baldwin D, Barnes A, Sewell HF, Fritsche HA, Robertson JFR. Technical validation of an autoantibody test for lung cancer. Ann Oncol. 2010 Aug;21(8):1687-1693. doi: 10.1093/annonc/mdp606. Epub 2010 Feb 2

[9] Murray, A., Chapman, C.J., Healey, G., Peek, L.J., Parsons, G., Baldwin, D., Barnes, A., Sewell, H.F., Fritsche, H.A. and Robertson, J.F. (2010) Technical Validation of an Autoantibody Test For Lung Cancer. Annals of Oncology, 21, 1687-1693. https://doi.org/10.1093/annonc/mdp606

[10] Pepe MS, Etzioni R, Feng Z, Potter JD, Thompson ML, Thornquist M, Winget M, Yasui Y. Phases of Biomarker Development for Early Detection of Cancer. JNCI J. Natl. Cancer Institute. Oxford University Press; 2001 [; 93: 1054-106 doi/10.1093/jnci/93.14.1054.

[11] Sullivan FM, Mair FS, Anderson W, Armory P, Briggs A, Chew C, Dorward A, Haughney J, Hogarth F, Kendrick D, Littleford R, McConnachie A, McCowan C, Mcmeekin N, Patel M, Rauchhaus P, Ritchie L, Robertson C, Robertson J, Robles-Zurita J, Sarvesvaran J, Sewell H, Sproule M, Taylor T, Tello A, Treweek S, Vedhara K, Schembri S; Early Diagnosis of Lung Cancer Scotland (ECLS) Team. Earlier diagnosis of lung cancer in a randomised trial of an autoantibody blood test followed by imaging. Eur Respir J. 2020 Jul 30:2000670. doi: 10.1183/13993003.00670-2020.

[12] Sullivan F, Farmer E, Mair FS, Treweek S, Kendrick D, Jackson C, Robertson C, Briggs A, McCowan C, Bedford L, Young B, Vedhara K, Gallant S, Littleford R, Robertson J, Sewell H, Dorward A, Sarvesvaran J, Schembri S. Detection in blood of autoantibodies to tumour antigens as a case-finding method in lung cancer using the EarlyCDT ${ }^{\circledR}$-Lung Test (ECLS): study protocol for a randomized controlled trial. BMC Cancer (2017) 17:187 DOI 10.1186/s12885-017-3175-y

[13] Kendrick S, Clarke J. The Scottish record linkage system.HealthBulletin (Edinburgh)1993;51:72-9.

[14] Mulholland RH, Vasileiou E, Simpson CR, Robertson C, Ritchie LD, Agrawal U, Woolhouse M, Murray JLK, Stagg HR, Docherty AB, McCowan C, Wood R, Stock SJ, Sheikh A. Cohort profile:

Early pandemic evaluation and enhanced surveillance of COVID-19 (EAVE II) database. Int J Epidemiol. 2021 Apr 16:dyab028. doi: 10.1093/ije/dyab028. 
[15] National Health Service (NHS). Community Health Index (CHI). Available online:

https://datadictionary.nhs.uk/attributes/community_health_index_number.html (last accessed 12.8.21)

[16] Data Linkage Service University of Dundee https://www.dundee.ac.uk/hic/datalinkageservice/ last accessed 12.8.21

[17] Qi X, Liu C, Jiang Z, Gu Y, Zhang G, Shao C, Yue H, Chen Z, Ma B, Liu D, Zhang L, Wang J, Xu D, Lei J, Li X, Huang H, Wang Y, Liu H, Yang J, Pan H, Liu W, Wang W, Li F, Zou S, Zhang H, Dong J. Multicenter analysis of clinical characteristics and outcomes in patients with COVID-19 who develop liver injury. J Hepatol. 2020 Aug;73(2):455-458. doi: 10.1016/j.jhep.2020.04.010.

[18] Shen B, Yi X, Sun Y, et al.

Proteomic and Metabolomic Characterization of COVID-19 Patient Sera.

Cell. 2020;182(1):59-72. e15.

\section{Tables}

\begin{tabular}{|c|c|c|c|c|c|c|}
\hline \multirow[b]{2}{*}{ Result of SARS-COV-2 test } & \multicolumn{2}{|c|}{ Positive } & \multicolumn{2}{|c|}{ Negativeative } & \multicolumn{2}{|c|}{ Control } \\
\hline & $\mathrm{N}$ & $\%$ & $\mathrm{~N}$ & $\%$ & $\mathrm{~N}$ & $\%$ \\
\hline Positive & 9 & 6.7 & 86 & 7.8 & 84 & 7.0 \\
\hline Negative & 126 & 93.3 & 1021 & 92.2 & 1110 & 93.0 \\
\hline Total & 135 & 100 & 1107 & 100 & 1194 & 100 \\
\hline \multicolumn{7}{|l|}{ Patient deceased } \\
\hline No & 131 & 97.0 & 1072 & 96.8 & 1155 & 96.7 \\
\hline Yes & 4 & 3.0 & 35 & 3.2 & 39 & 3.3 \\
\hline Total & 135 & 100 & 1107 & 100 & 1194 & 100 \\
\hline
\end{tabular}

There were no significant differences discerned between SARS-CoV-2 Test results and EarlyCDT-Lung test results (positive / negative) ( $p=0.734)$; or likewise between

SARS-CoV-2 Test results and EarlyCDT-Lung test results (positive / negative / control) ( $p=0.779$ ); or finally between SARS-CoV-2 Test results and Treatment (tested / not tested) ( $p=0.587)$. An additional analysis of ICU admissions detected no significant differences between those who tested positive and negative. 
There was no difference in COVID -19 positivity or death rates amongst those diagnosed with lung cancer with positive and negative EarlyCDT results.

\begin{tabular}{|c|c|c|c|c|c|c|c|c|}
\hline \multirow[b]{3}{*}{ Stage } & \multicolumn{8}{|c|}{ ECDT-Lung Test result } \\
\hline & \multicolumn{2}{|c|}{ Test-POSITIVE } & \multicolumn{2}{|c|}{ Test-NEGATIVE } & \multicolumn{2}{|c|}{ Not tested } & \multicolumn{2}{|c|}{ Total } \\
\hline & $N$ & $\%$ & $N$ & $\%$ & $N$ & $\%$ & $N$ & $\%$ \\
\hline Stage 3 & 0 & $(0.0)$ & 1 & (14.3) & 4 & $(44.4)$ & 5 & $(27.8)$ \\
\hline Stage 4 & 0 & $(0.0)$ & 1 & (14.3) & 0 & $(0.0)$ & 1 & (5.6) \\
\hline Other & 2 & $(0.0)$ & 5 & (71.4) & 5 & $(55.6)$ & 12 & $(66.7)$ \\
\hline Total & 2 & (100) & 7 & $(100)$ & 9 & $(100)$ & 18 & $(100)$ \\
\hline Covid result & $N$ & $\%$ & $\mathrm{~N}$ & $\%$ & $N$ & $\%$ & $N$ & $\%$ \\
\hline Test-POSITIVE & 0 & $(0.0)$ & 1 & $(14.3)$ & 1 & $(11.1)$ & 2 & (11.1) \\
\hline Test-NEGATIVE & 2 & $(100.0)$ & 6 & (85.7) & 8 & $(88.9)$ & 16 & $(88.9)$ \\
\hline Total & 2 & $(100)$ & 7 & $(100)$ & 9 & $(100)$ & 18 & $(100)$ \\
\hline \multicolumn{9}{|c|}{$\mathrm{OR}^{\star \star}=0.00(0.00,66.5) \quad p=1.0$} \\
\hline Hospitalised* & $N$ & $\%$ & $N$ & $\%$ & $N$ & $\%$ & $N$ & $\%$ \\
\hline No & 0 & $(0.0)$ & 4 & $(57.1)$ & 3 & (33.3) & 7 & $(38.9)$ \\
\hline Yes & 2 & $(100.0)$ & 3 & $(42.9)$ & 6 & $(66.7)$ & 11 & $(61.1)$ \\
\hline Total & 2 & $(100)$ & 7 & $(100)$ & 9 & $(100)$ & 18 & $(100)$ \\
\hline \multicolumn{9}{|c|}{$\mathrm{OR}^{\star \star}=0.00(0.00,4.20) \quad p=0.44$} \\
\hline Death* & $N$ & $\%$ & $N$ & $\%$ & $N$ & $\%$ & $N$ & $\%$ \\
\hline No & 2 & $(100.0)$ & 6 & $(85.7)$ & 9 & $(100.0)$ & 17 & $(94.4)$ \\
\hline Yes & 0 & $(0.0)$ & 1 & (14.3) & 0 & $(0.0)$ & 1 & (5.6) \\
\hline Total & 2 & $(100)$ & 7 & $(100)$ & 9 & $(100)$ & 18 & $(100)$ \\
\hline $\mathrm{OR}^{\star *}=9999(0.0$ & 5,999 & $p=1$ & & & & & & \\
\hline
\end{tabular}


* Event within 28 days of a Covid test

** Odds ratio (Test-POSITIVE v. Test-NEGATIVE)

Nil significance found.

Table 4 shows no difference in COVID -19 positivity or death rates amongst those diagnosed with COPD with positive and negative EarlyCDT results.

\begin{tabular}{|c|c|c|c|c|c|c|c|c|}
\hline \multirow[b]{3}{*}{ Covid result } & \multicolumn{8}{|c|}{ ECDT-Lung Test result } \\
\hline & \multicolumn{2}{|c|}{ Test-POSITIVE } & \multicolumn{2}{|c|}{ Test-NEGATIVE } & \multicolumn{2}{|c|}{ Not tested } & \multicolumn{2}{|c|}{ Total } \\
\hline & $N$ & $\%$ & $N$ & $\%$ & $N$ & $\%$ & $N$ & $\%$ \\
\hline Positive & 1 & $(6.6)$ & 3 & $(2.6)$ & 9 & $(8.3)$ & 13 & $(5.4)$ \\
\hline Negative & 15 & $(93.8)$ & 113 & $(97.4)$ & 100 & $(91.7)$ & 228 & $(94.6)$ \\
\hline Total & 16 & $(100)$ & 116 & $(100)$ & 109 & $(100)$ & 241 & $(100)$ \\
\hline \multicolumn{9}{|c|}{$\mathrm{OR}^{\star \star}=2.51(0.0913,24.13) \quad p=0.407$} \\
\hline Hospitalised* & $N$ & $\%$ & $N$ & $\%$ & $N$ & $\%$ & $N$ & $\%$ \\
\hline No & 9 & $(56.3)$ & 68 & $(58.6)$ & 58 & $(53.2)$ & 135 & $(56.0)$ \\
\hline Yes & 7 & $(43.8)$ & 48 & $(41.4)$ & 51 & $(46.8)$ & 106 & $(44.0)$ \\
\hline Total & 16 & $(100)$ & 116 & $(100)$ & 109 & $(100)$ & 241 & $(100)$ \\
\hline \multicolumn{9}{|c|}{$\mathrm{OR}^{\star \star}=0.908(0.312,2.858) \quad p=1.0$} \\
\hline Death* & $N$ & $\%$ & $N$ & $\%$ & $N$ & $\%$ & $N$ & $\%$ \\
\hline No & 16 & $(100.0)$ & 110 & $(94.8)$ & 105 & $(96.3)$ & 231 & $(95.9)$ \\
\hline Yes & 0 & $(0.0)$ & 6 & $(5.2)$ & 4 & (3.7) & 10 & $(4.1)$ \\
\hline Total & 16 & $(100)$ & 116 & $(100)$ & 109 & $(100)$ & 241 & $(100)$ \\
\hline \multicolumn{9}{|c|}{$\mathrm{OR}^{\star \star}=9999(0.176,9999) \quad p=1.0$} \\
\hline
\end{tabular}

* Event within 28 days of a Covid test

** Odds ratio (Test-POSITIVE v. Test-NEGATIVE) 
Nil significance found.

Page 9/9 